\title{
Synthesis and Photophysical Properties of Meso-
}

\author{
Substituted Bisporphyrin. Comparative Study of
}

\section{Phosphorescence Quenching for Dioxygen Sensing.}

Sébastien Faure, Christine Stern, Roger Guilard and Pierre D. Harvey

Table S1. Emission Data of DPSN Bisporphyrins and Related Compounds.

Some spectra of compounds $2,3,5-9$.

4,6-diformyldibenzothiophene 2

${ }^{1} \mathrm{H}$ NMR, DMSO, $298 \mathrm{~K}$

4,6-bis[(2,2'-dipyrryl)methyl]dibenzothiophene 3

${ }^{1} \mathrm{H},{ }^{13} \mathrm{C}\left\{{ }^{1} \mathrm{H}\right\}$ and ${ }^{2} \mathrm{D}(\mathrm{C}-\mathrm{H}) \mathrm{NMR}, \mathrm{CDCl}_{3}, 298 \mathrm{~K}$; MS (EI) and MS (MALDI-TOF)

4,6-bis[2,2'-bis(1-(p-methylbenzoyl)pyrryl)methyl])dibenzothiophene $\mathbf{5}$

${ }^{1} \mathrm{H}$ NMR, $\mathrm{CDCl}_{3}, 298 \mathrm{~K}$; MS (MALDI-TOF) ; IR (ATR)

4,6-bis(10-mesityl-5,15-di-p-tolylporphyrinyl)dibenzothiophene 6

${ }^{1} \mathrm{H}$ NMR, $\mathrm{CDCl}_{3}, 298 \mathrm{~K}$; MS (MALDI-TOF)

4,6-bis(zinc(II)-10-mesityl-5,15-di-p-tolylporphyrinyl)dibenzothiophene 7

${ }^{1} \mathrm{H}$ NMR, $\mathrm{CDCl}_{3}$, $298 \mathrm{~K}$; MS (MALDI-TOF)

4,6-bis(palladium(II)-10-mesityl-5,15-di-p-tolylporphyrinyl)dibenzothiophene 8

${ }^{1} \mathrm{H}$ and ${ }^{13} \mathrm{C}\left\{{ }^{1} \mathrm{H}\right\}$ NMR, $\mathrm{CDCl}_{3}, 298 \mathrm{~K}$; MS (MALDI-TOF)

4,6-bis(copper(II)-10-mesityl-5,15-di-p-tolylporphyrinyl)dibenzothiophene 9

EPR, 100 K, DPPH 3427.49 ; MS (MALDI-TOF) 
Table S1. Emission Data of DPSN Bisporphyrins and Related Compounds. ${ }^{a}$

\begin{tabular}{|c|c|c|c|c|c|c|}
\hline \multirow{2}{*}{ Compound } & \multicolumn{2}{|c|}{ Emission $^{\mathrm{e}} \lambda_{\max }$} & \multicolumn{2}{|c|}{ Quantum yields ${ }^{\mathrm{b}}$} & \multicolumn{2}{|c|}{ Lifetime $^{\mathrm{f}} \tau_{\mathrm{F}}(\mathrm{ns}), \tau_{\mathrm{P}}(\mu \mathrm{s})$} \\
\hline & $298 \mathrm{~K}$ & $77 \mathrm{~K}$ & $298 \mathrm{~K}$ & $77 \mathrm{~K}$ & $298 \mathrm{~K}$ & $77 \mathrm{~K}$ \\
\hline $\mathrm{H}_{4} \mathrm{DPSN}$ & 655,719 & 655,715 & 0.06860 & 0.1310 & 12.43 & 13.34 \\
\hline$(\mathrm{Zn})_{2} \mathrm{DPSN}$ & 602,654 & 611,670 & 0.02843 & 0.0574 & 2.46 & 1.45 \\
\hline$(\mathrm{Pd})_{2} \mathrm{DPSN}$ & 699 & 688 & 0.03705 & 0.1551 & 506.00 & 1388.00 \\
\hline$(\mathrm{Cu})_{2} \mathrm{DPSN}$ & - & 729 & - & $<0.0001$ & - & 45.5 \\
\hline $\mathrm{H}_{2} \mathrm{TPP}$ & $652,718^{1, \mathrm{~d}}$ & $645,716^{2, \mathrm{~d}}$ & 0.11 & 0.1140 & $16^{3, \mathrm{~d}}$ & \\
\hline (Zn)TPP & & & 0.033 & & $1.8^{3, \mathrm{~d}}$ & \\
\hline (Pd)TPP & 696, 772 & 680,755 & 0.02 & 0.17 & 258.67 & 1320 \\
\hline$(\mathrm{Cu}) \mathrm{TPP}$ & - & $747^{4, \mathrm{c}}$ & - & $0.06^{4, \mathrm{c}}$ & - & $600^{4, c}$ \\
\hline $\mathrm{H}_{2} \mathrm{P}$ & 629, 696 & 623,690 & 0.0892 & 0.0862 & 17.3 & 23.3 \\
\hline$(\mathrm{Zn}) \mathrm{P}$ & 580,635 & $581,639,721$ & 0.0214 & 0.0266 & 1.7 & 1.94 \\
\hline$(\mathrm{Pd}) \mathrm{P}$ & - & $\begin{array}{l}\text { 659, 691, 712, } \\
731\end{array}$ & - & 0.5576 & 25 & 1872 \\
\hline $\mathrm{H}_{4} \mathrm{DPS}$ & 629, 697 & 623, 689 & 0.0887 & 0.0838 & 18.01 & 23.6 \\
\hline$(\mathrm{Zn})_{2} \mathrm{DPS}$ & 581, 636 & 584,643 & 0.0203 & 0.0226 & 1.95 & 1.85 \\
\hline$(\mathrm{Pd})_{2} \mathrm{DPS}$ & 669 & $\begin{array}{l}660,694,713, \\
735\end{array}$ & 0.04335 & 0.1052 & 210.50 & 1915.00 \\
\hline
\end{tabular}

a) In 2-MeTHF, $\lambda_{\text {excitation }}=510 \mathrm{~nm}$ for $\mathrm{H}_{2} \mathrm{DPSN}$ and the studied palladium porphyrins, $\lambda_{\text {excitation }}=540$ $\mathrm{nm}$ for copper and zinc porphyrins; the quantum yield was evaluated by reference to $\mathrm{H}_{2} \mathrm{TPP}(0.11)^{1,3,5}$ and the quantum yield for $\mathrm{H}_{2} \mathrm{TPP}(0.11)$ at $77 \mathrm{~K}$ was verified by reference to (Pd)TPP $(0.17 ; 77 \mathrm{~K}$; $\mathrm{MCH}),{ }^{6,7}$

b) Plain text for fluorescence data, italic text for phosphorescence data; the uncertainties in the values of the quantum yields are $\pm 10 \%$.

c) In methylcyclohexane (MCH).

d) In benzene.

e) The uncertainties in the values of $\lambda_{\max }$ are $\pm 1 \mathrm{~nm}$.

f) Plain text for fluorescence data (ns), italic text for phosphorescence data ( $\mu \mathrm{s})$, the uncertainties in the values of the lifetimes are $\pm 10 \%$. 


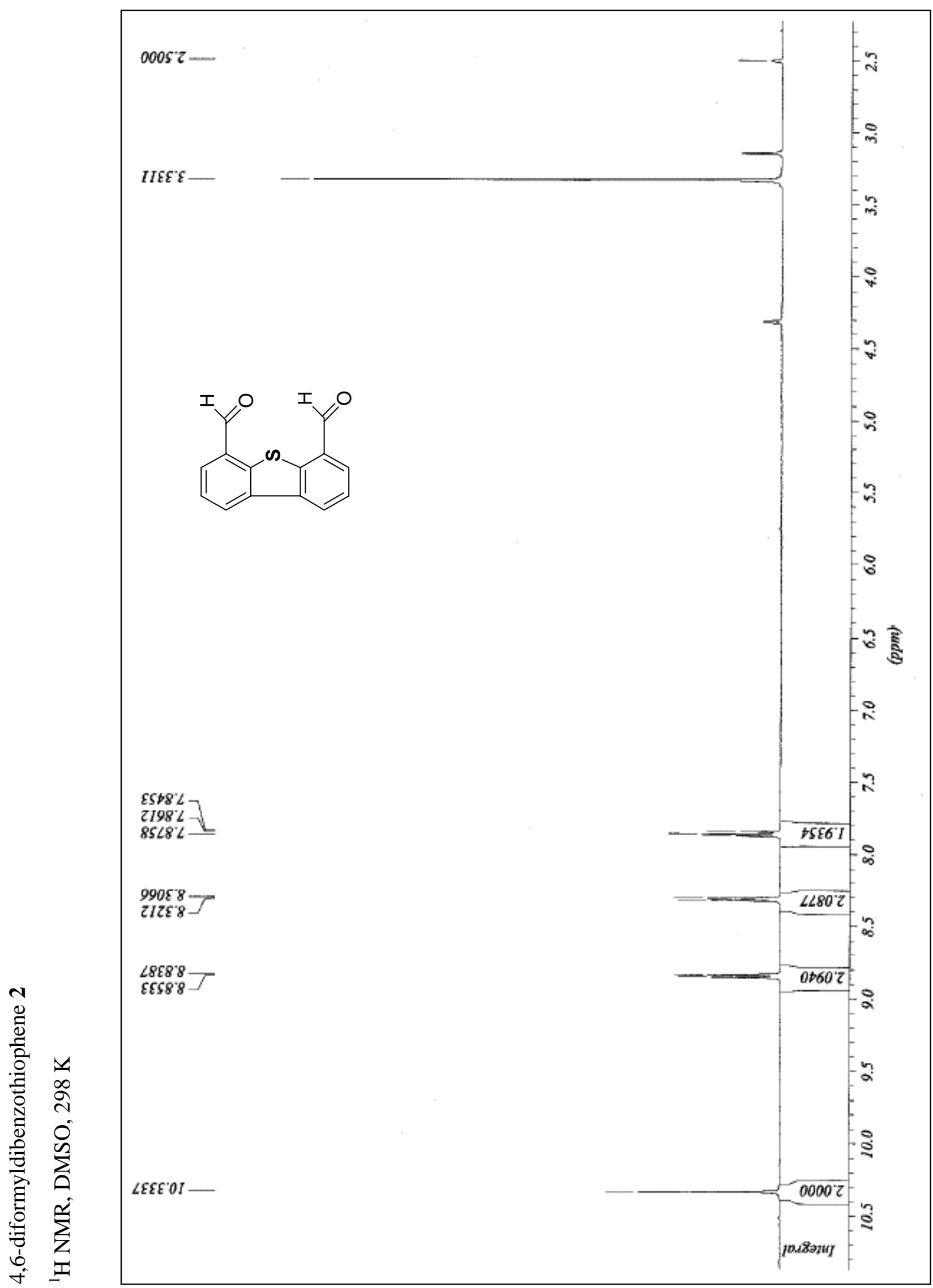




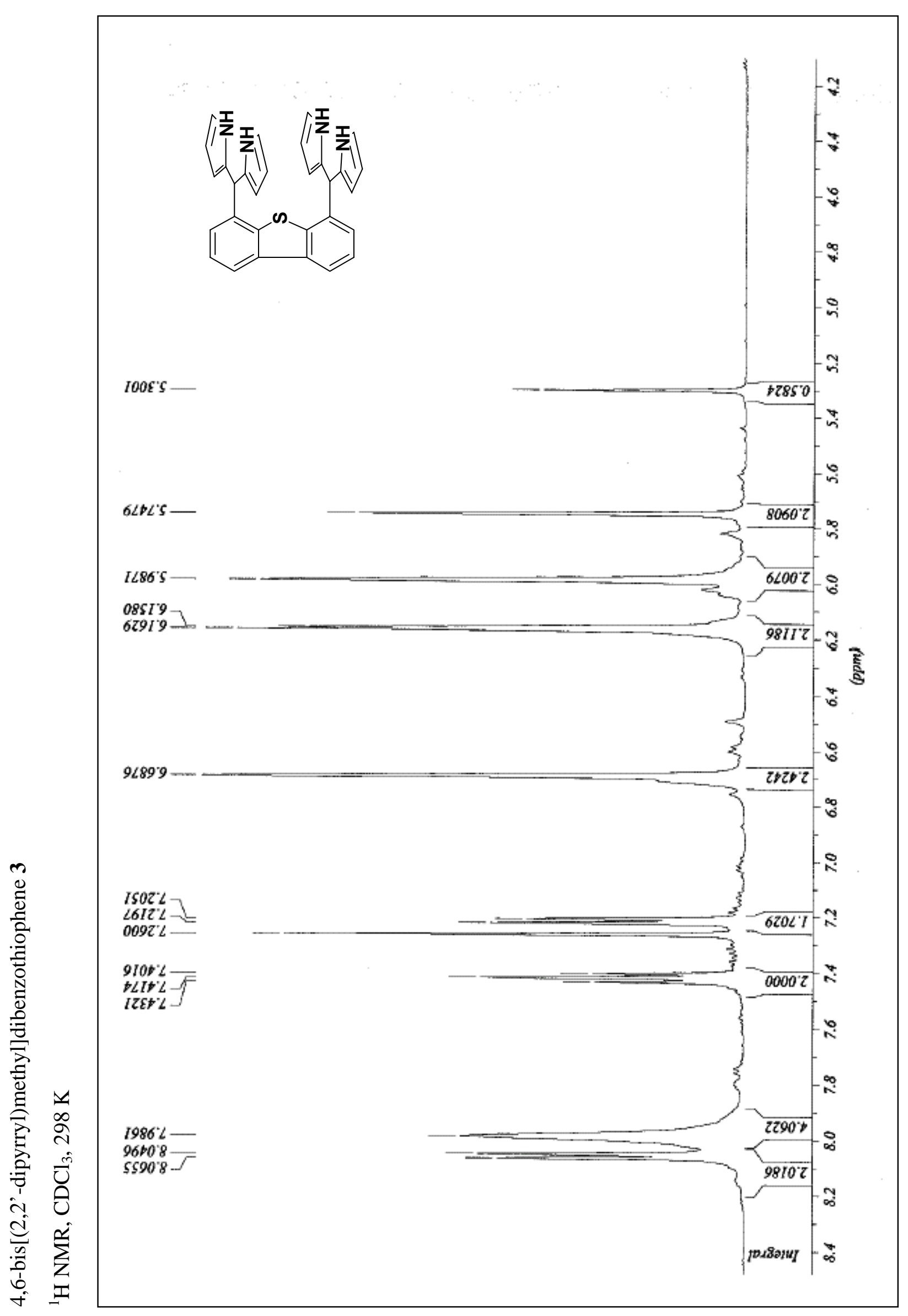




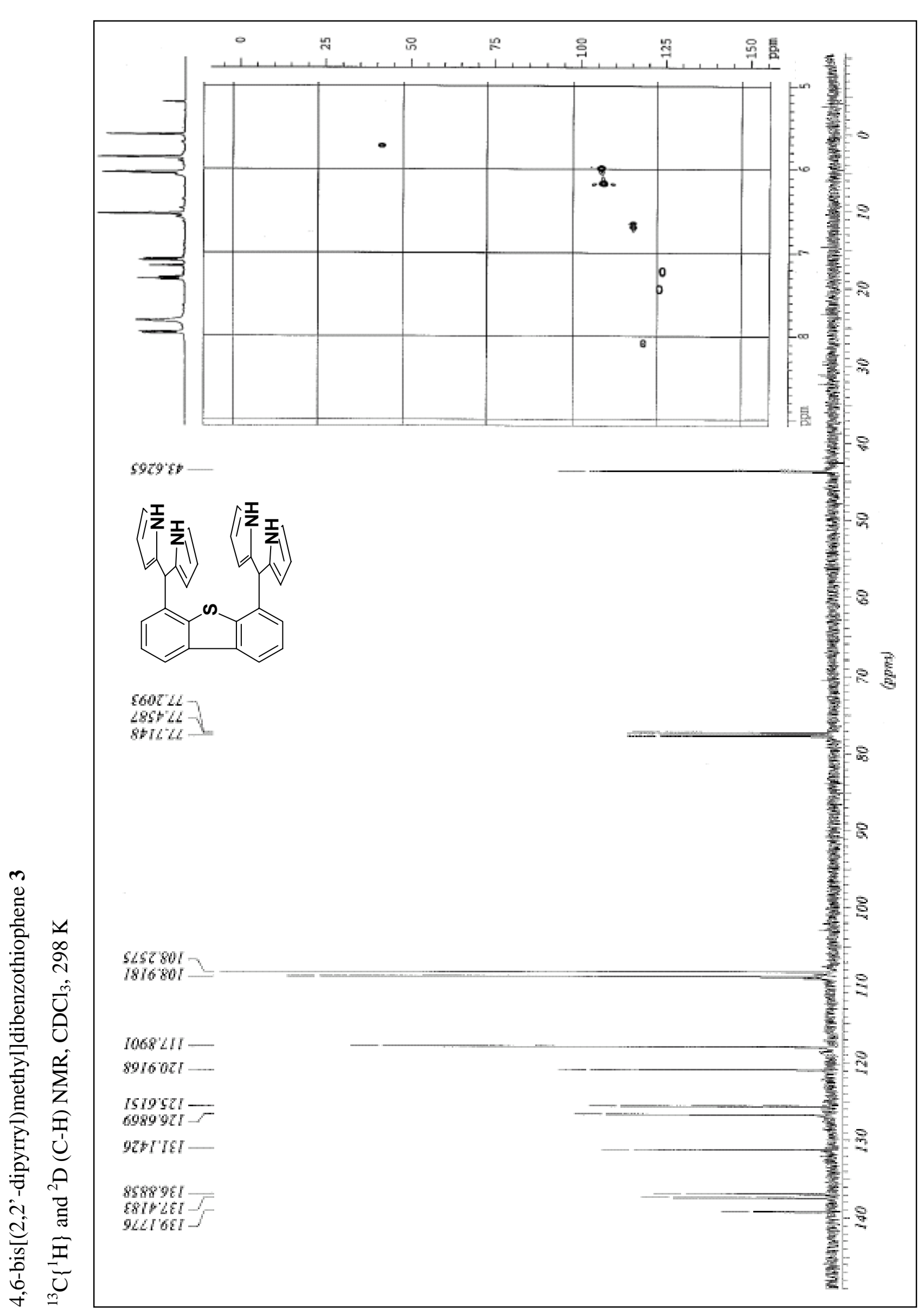




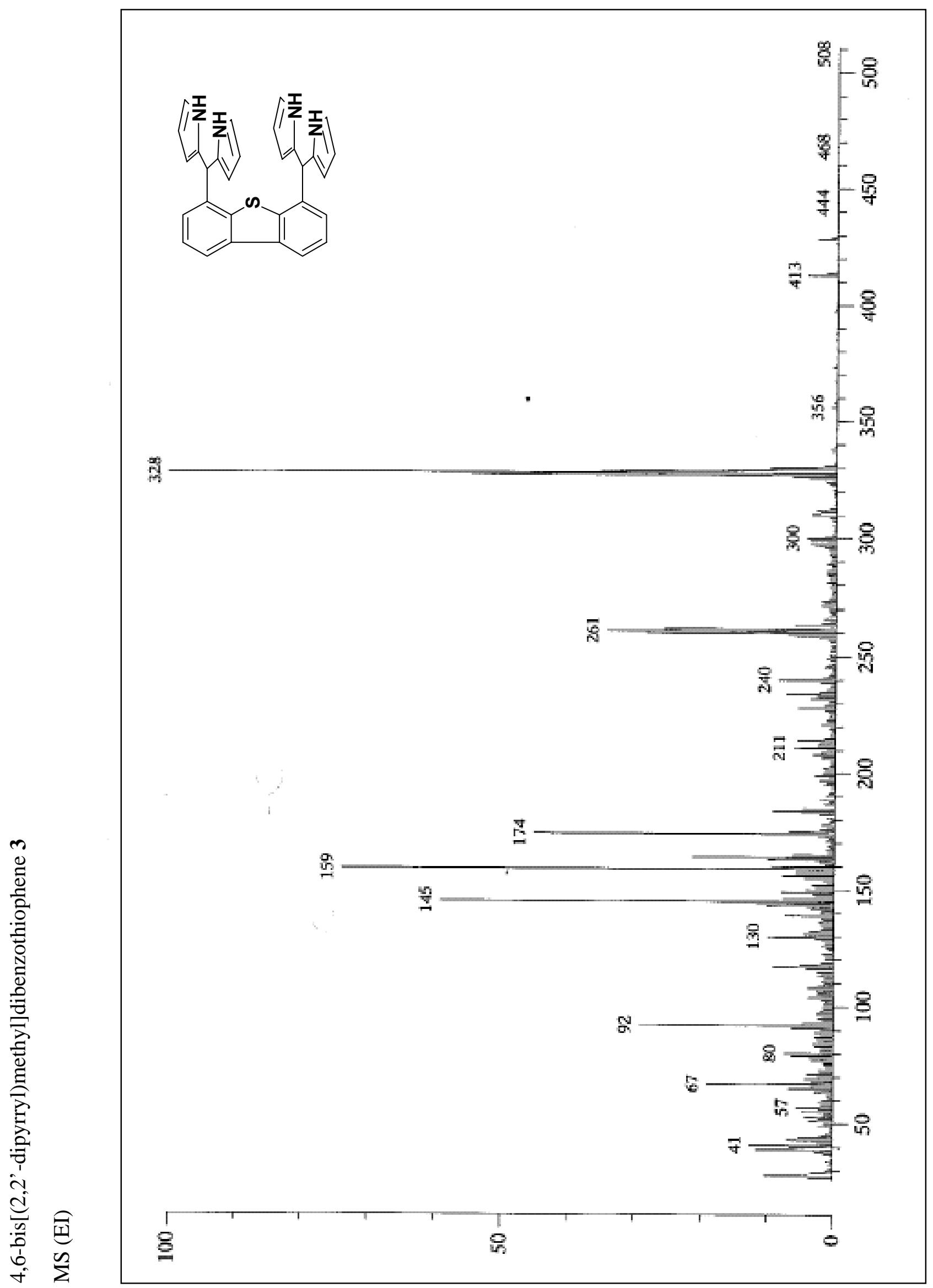




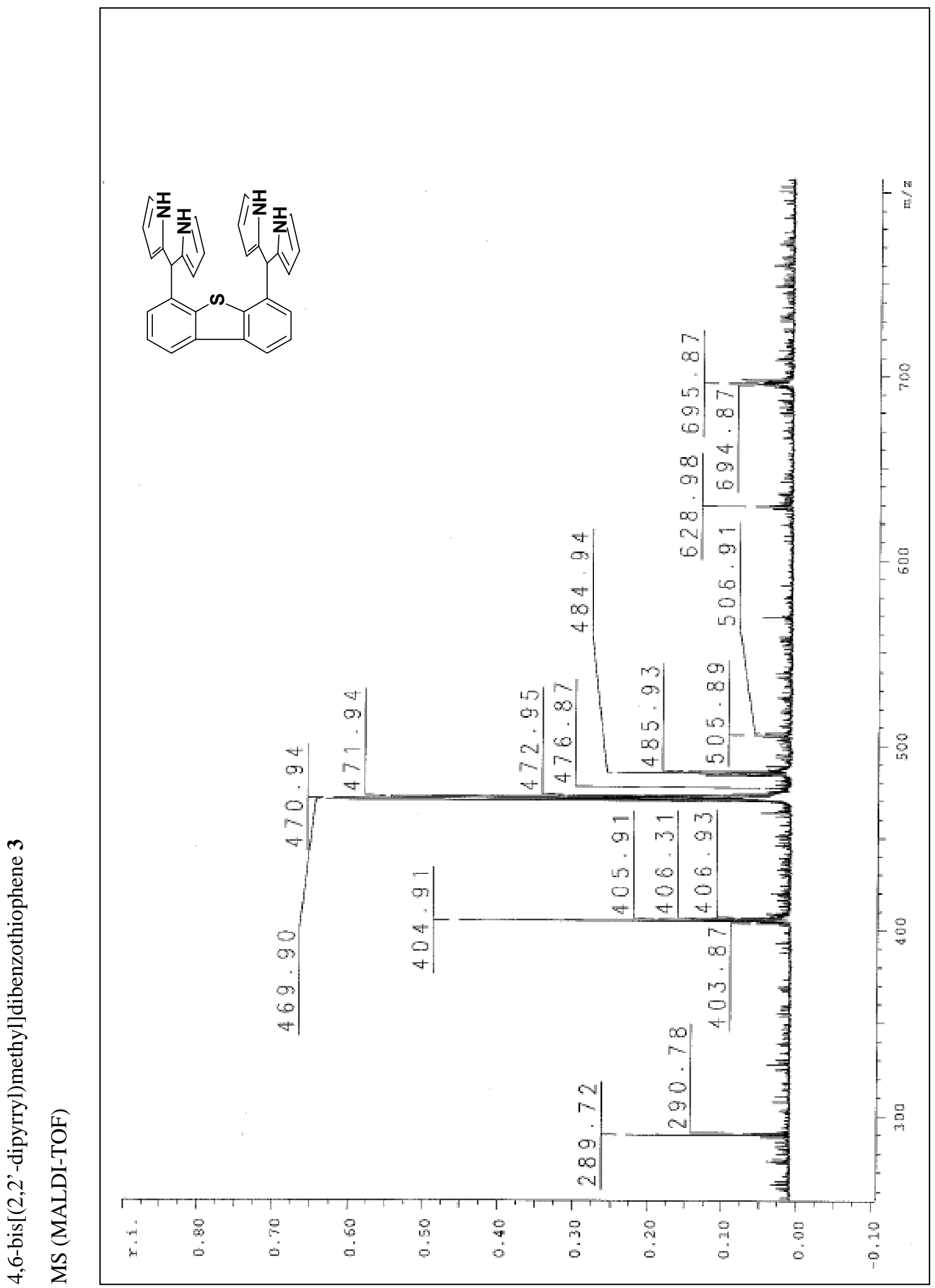




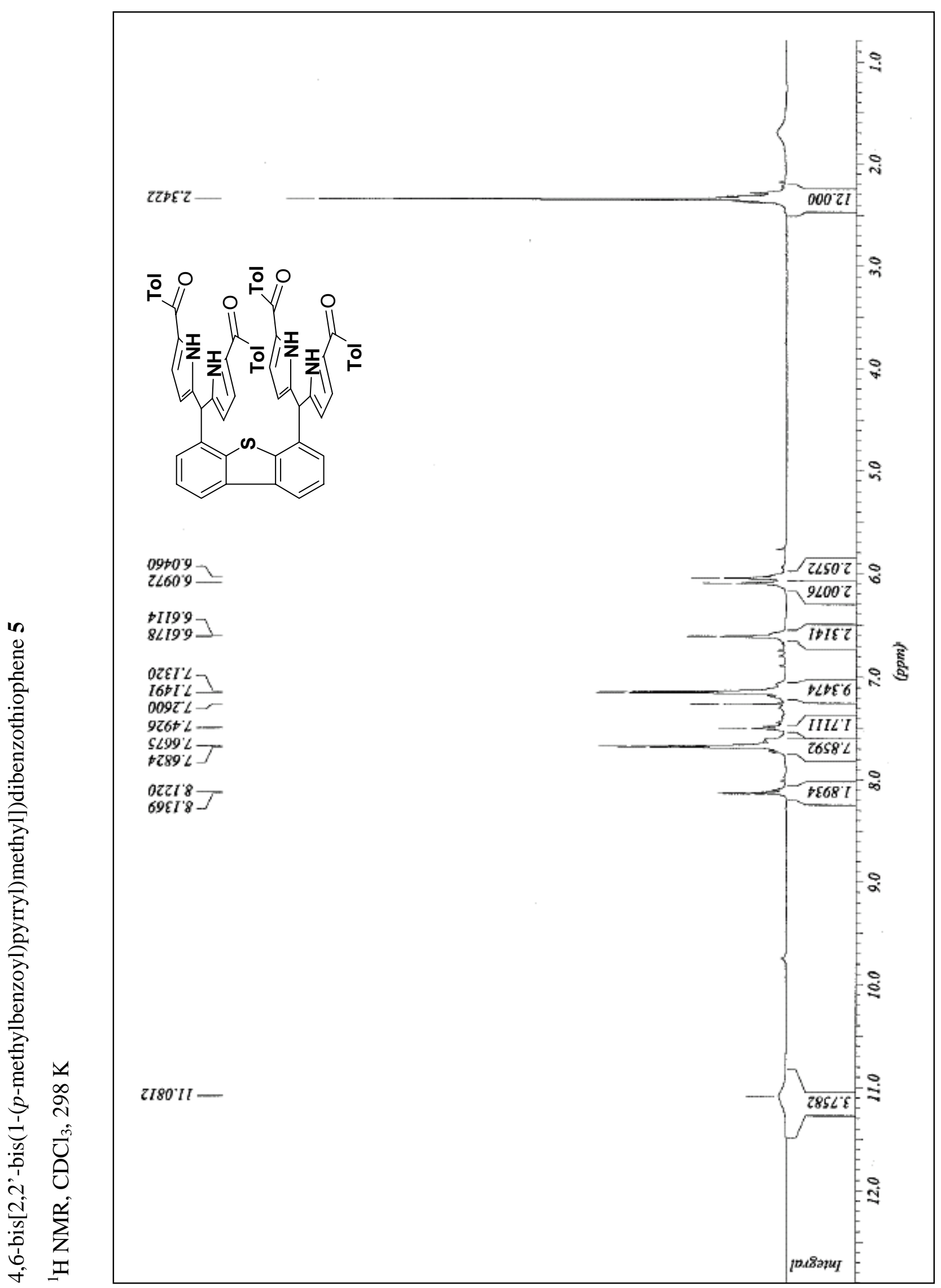




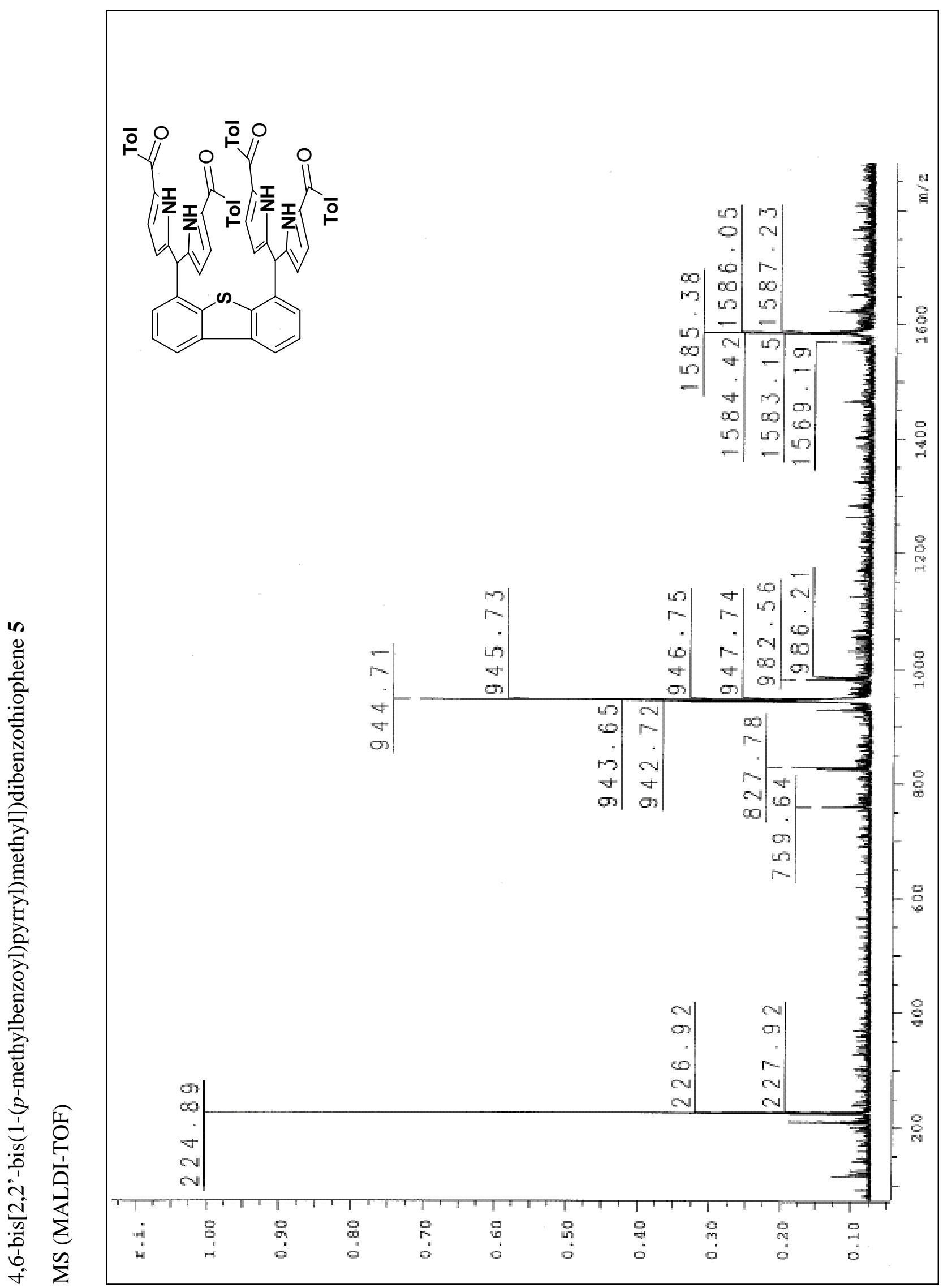




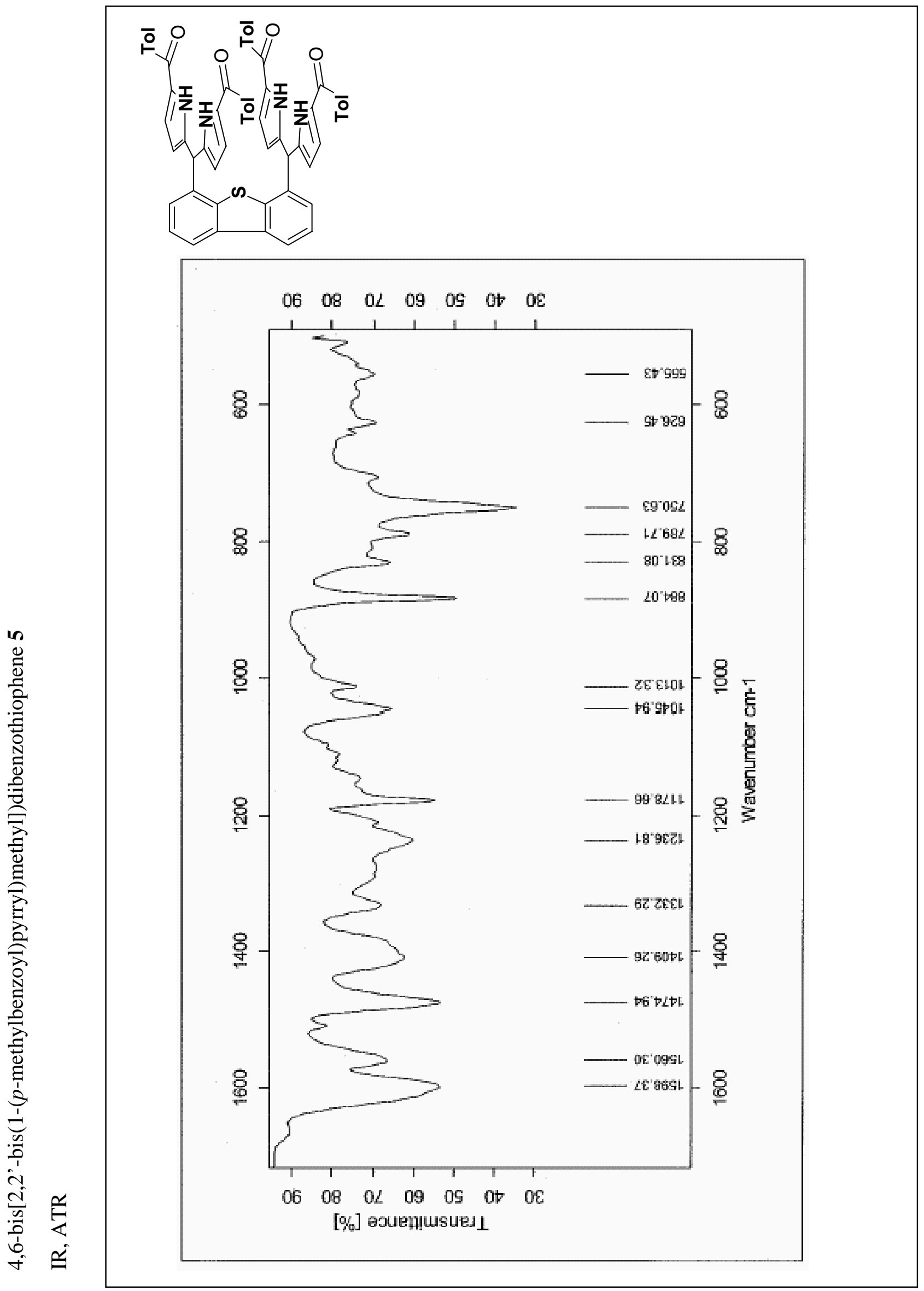




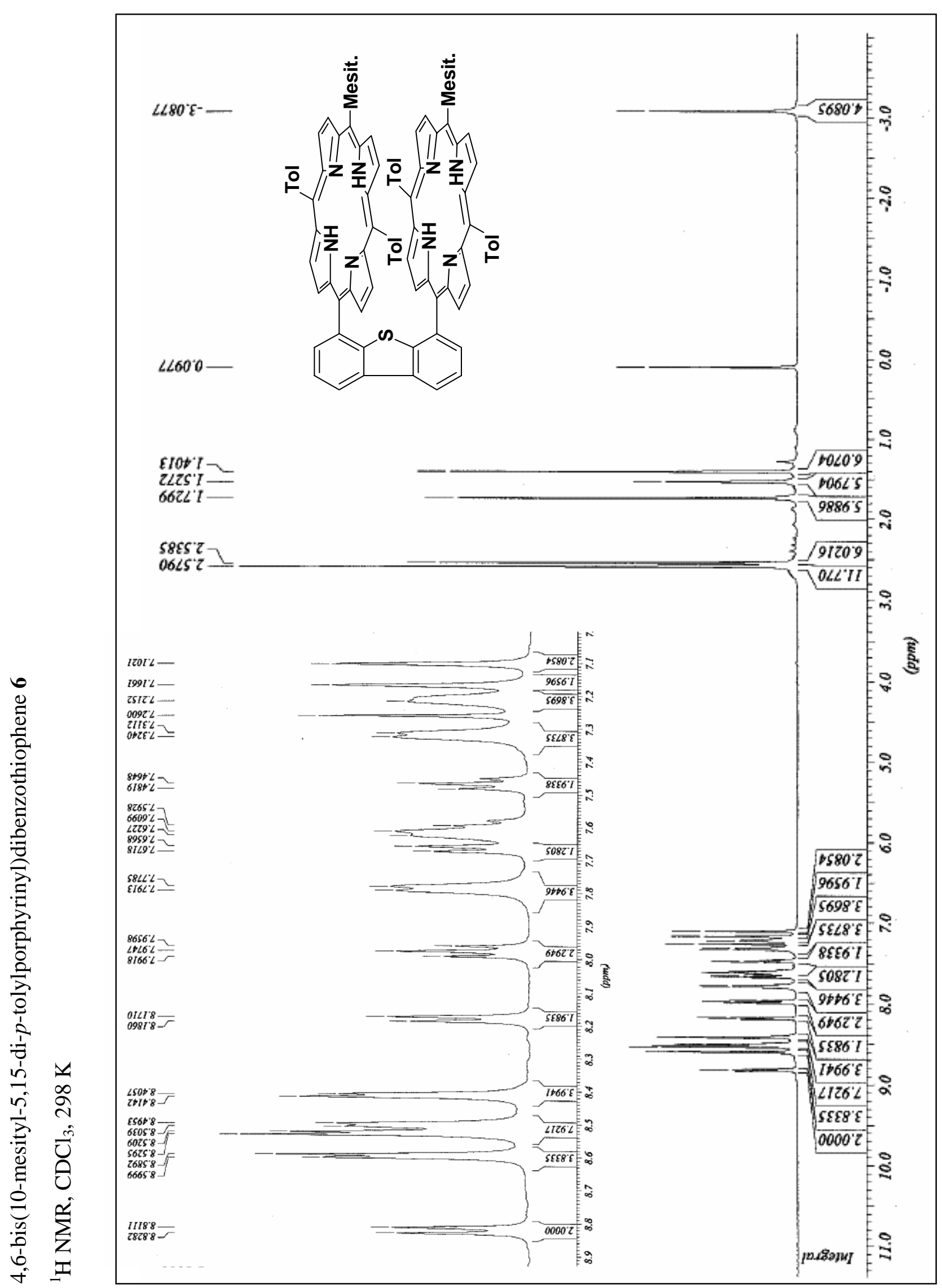




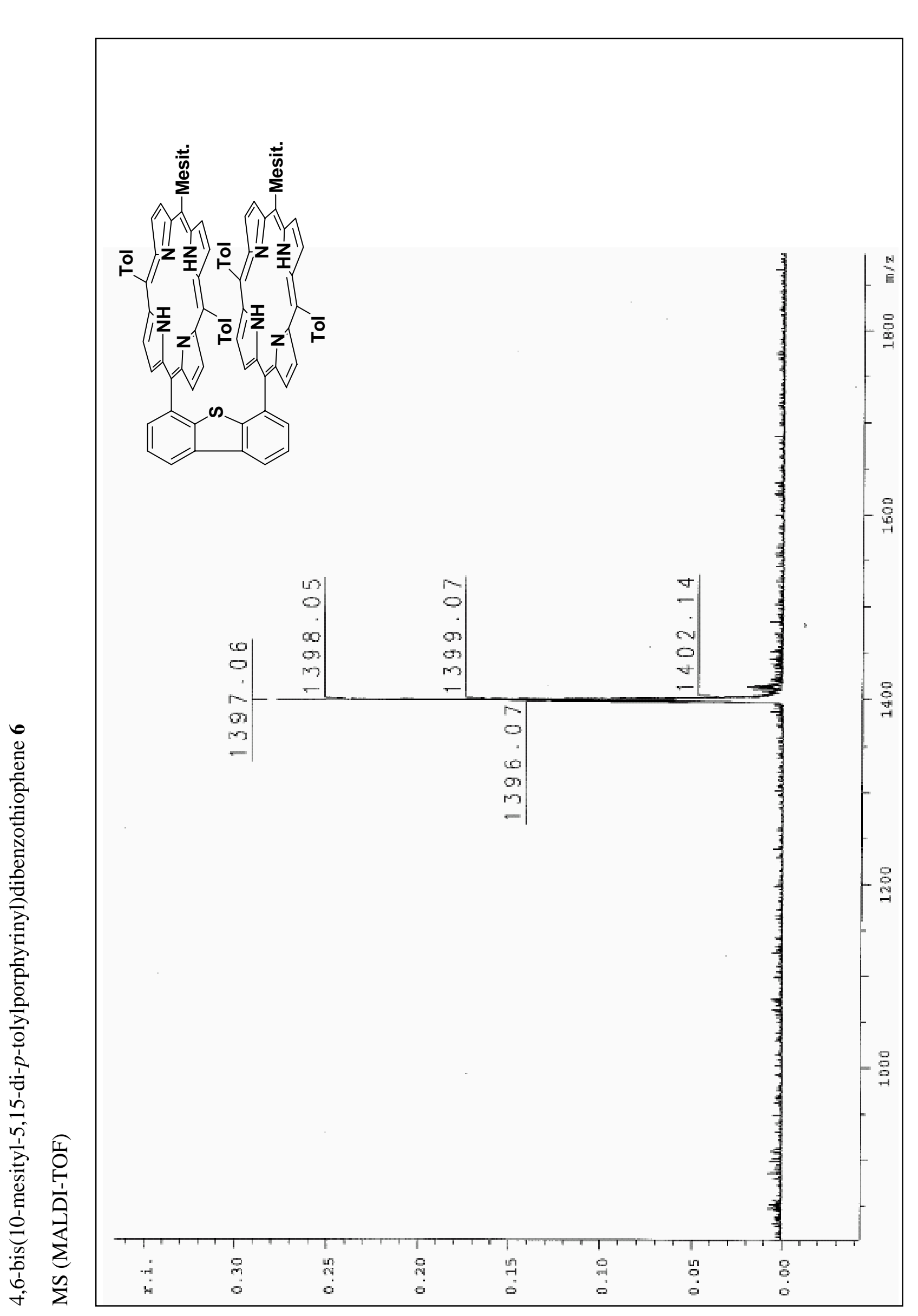




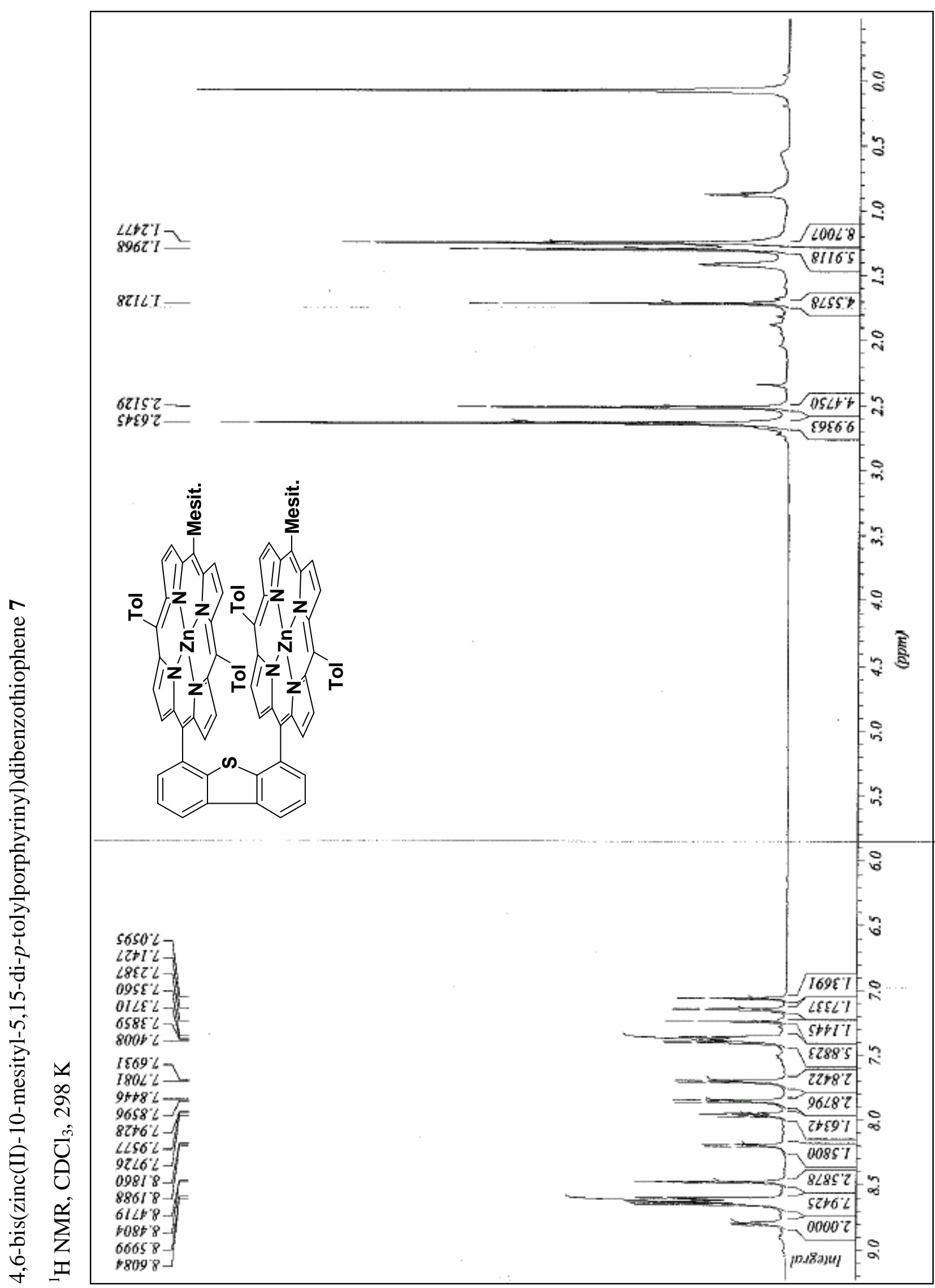




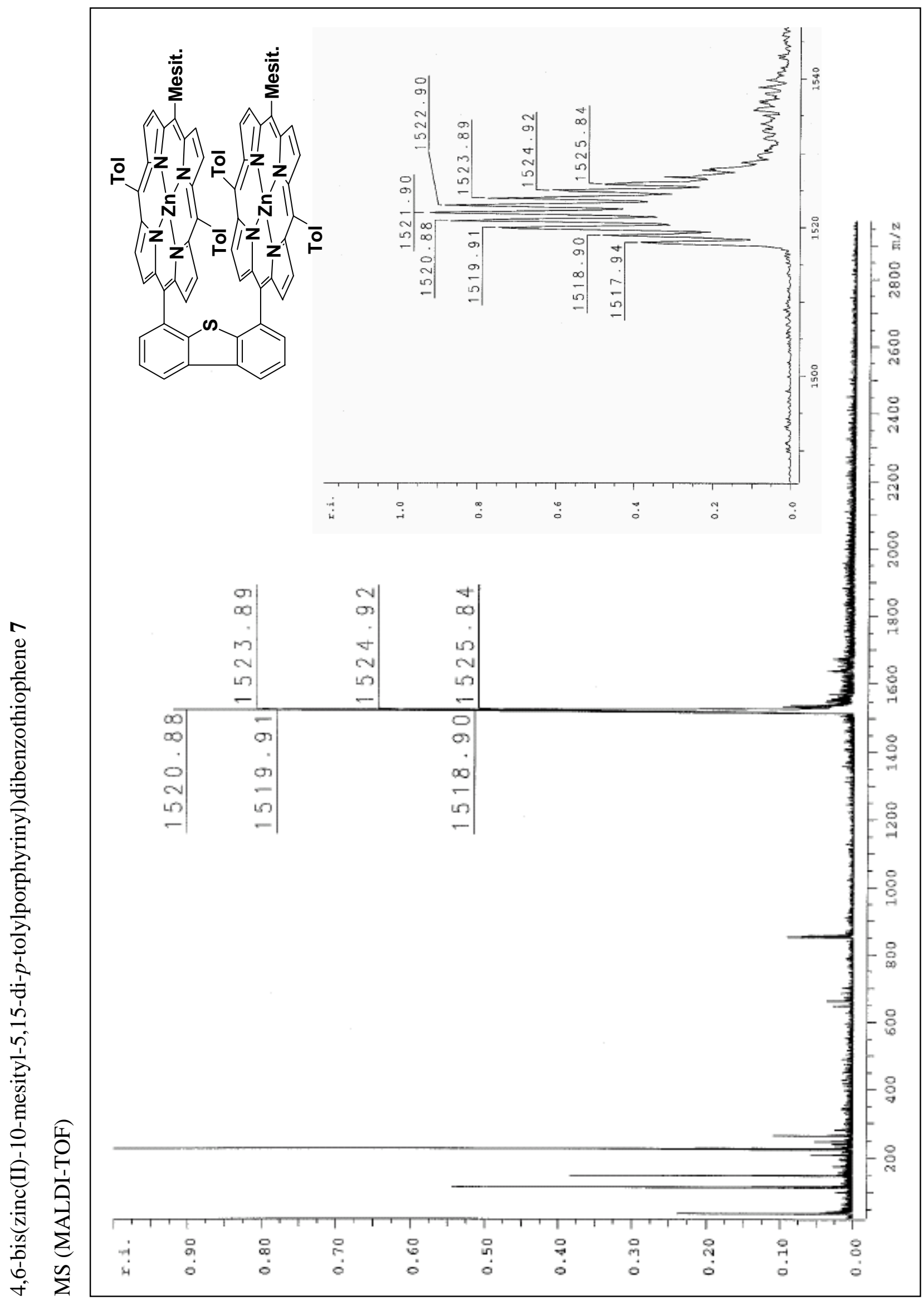




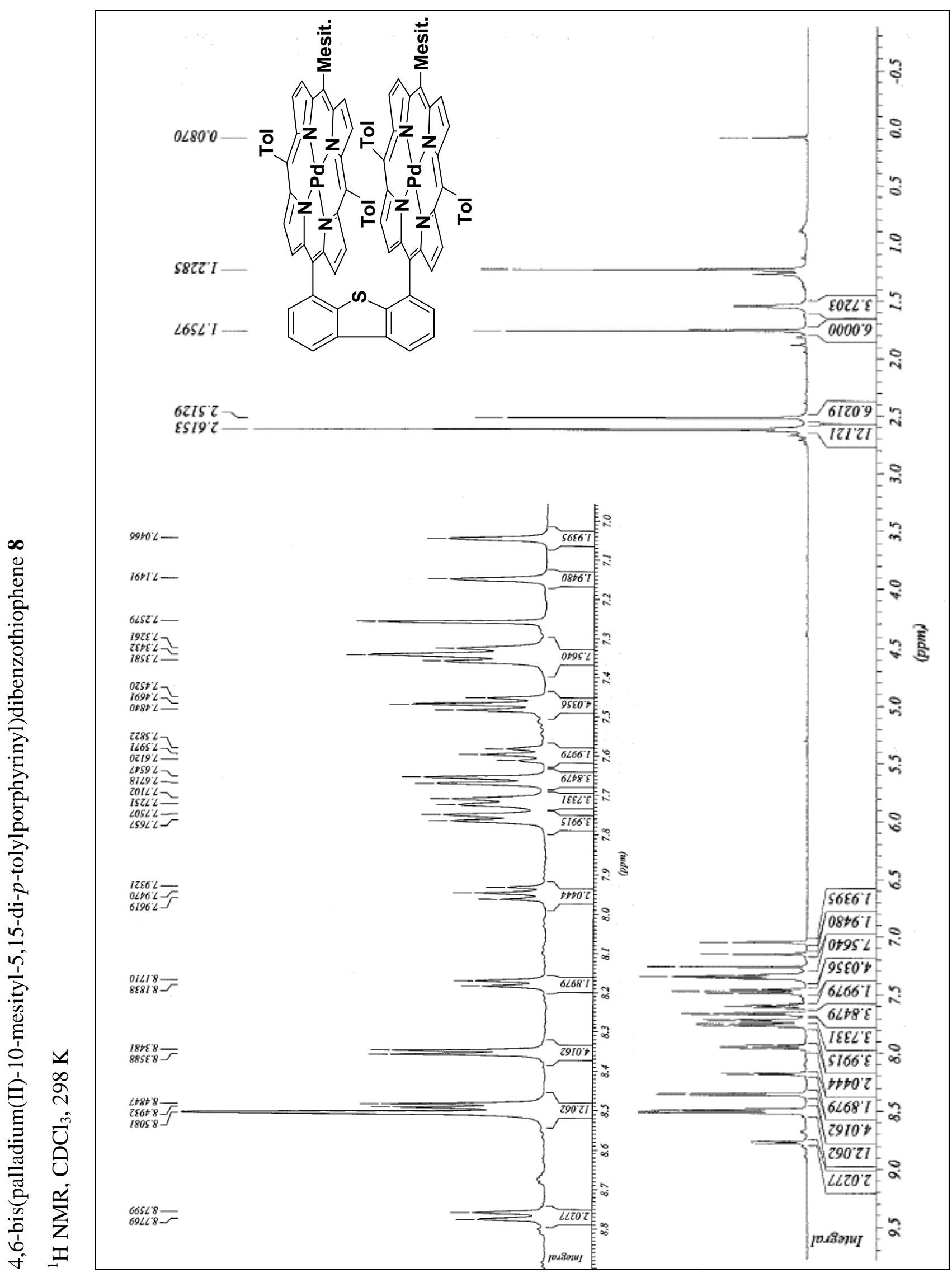




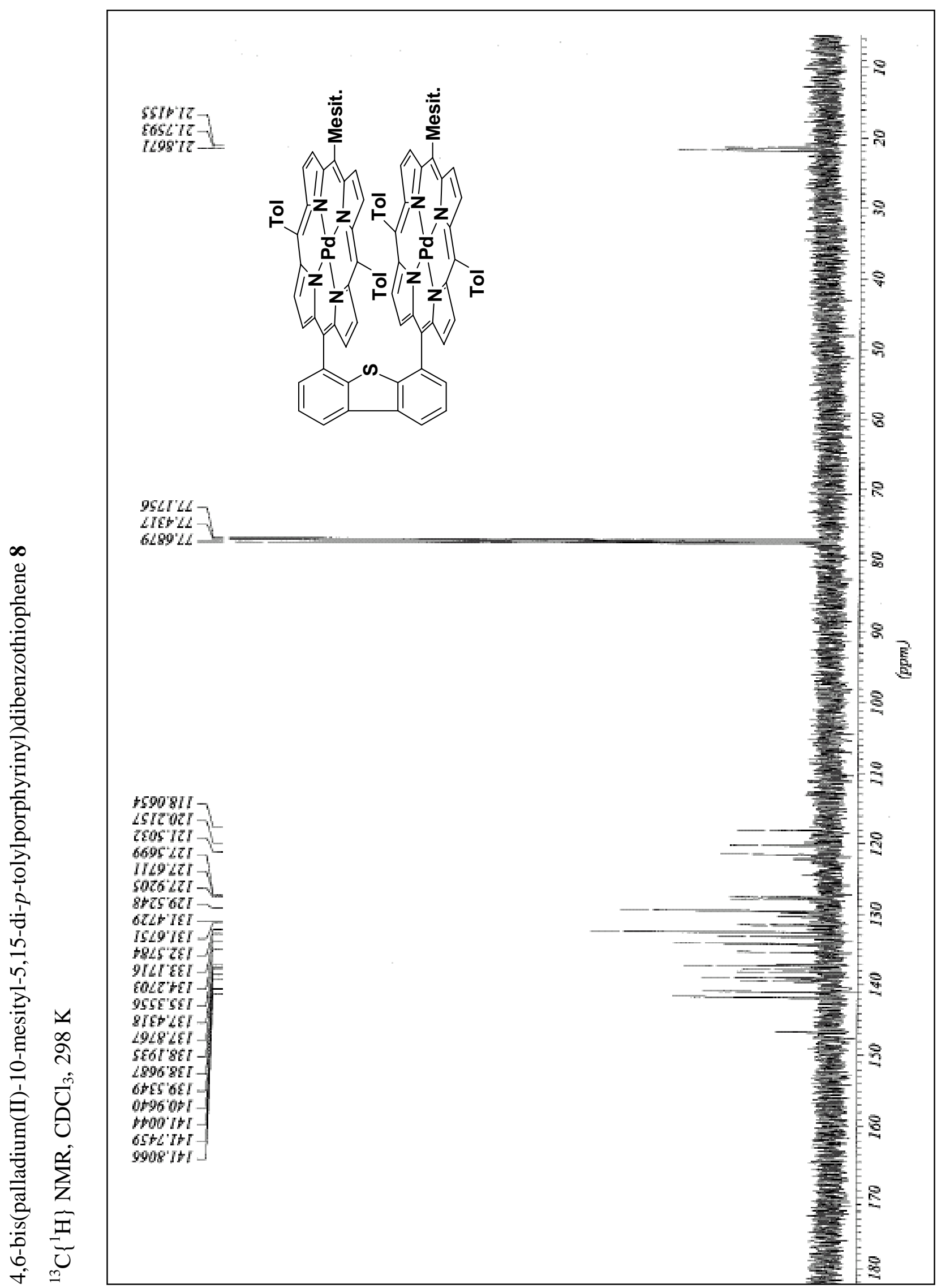




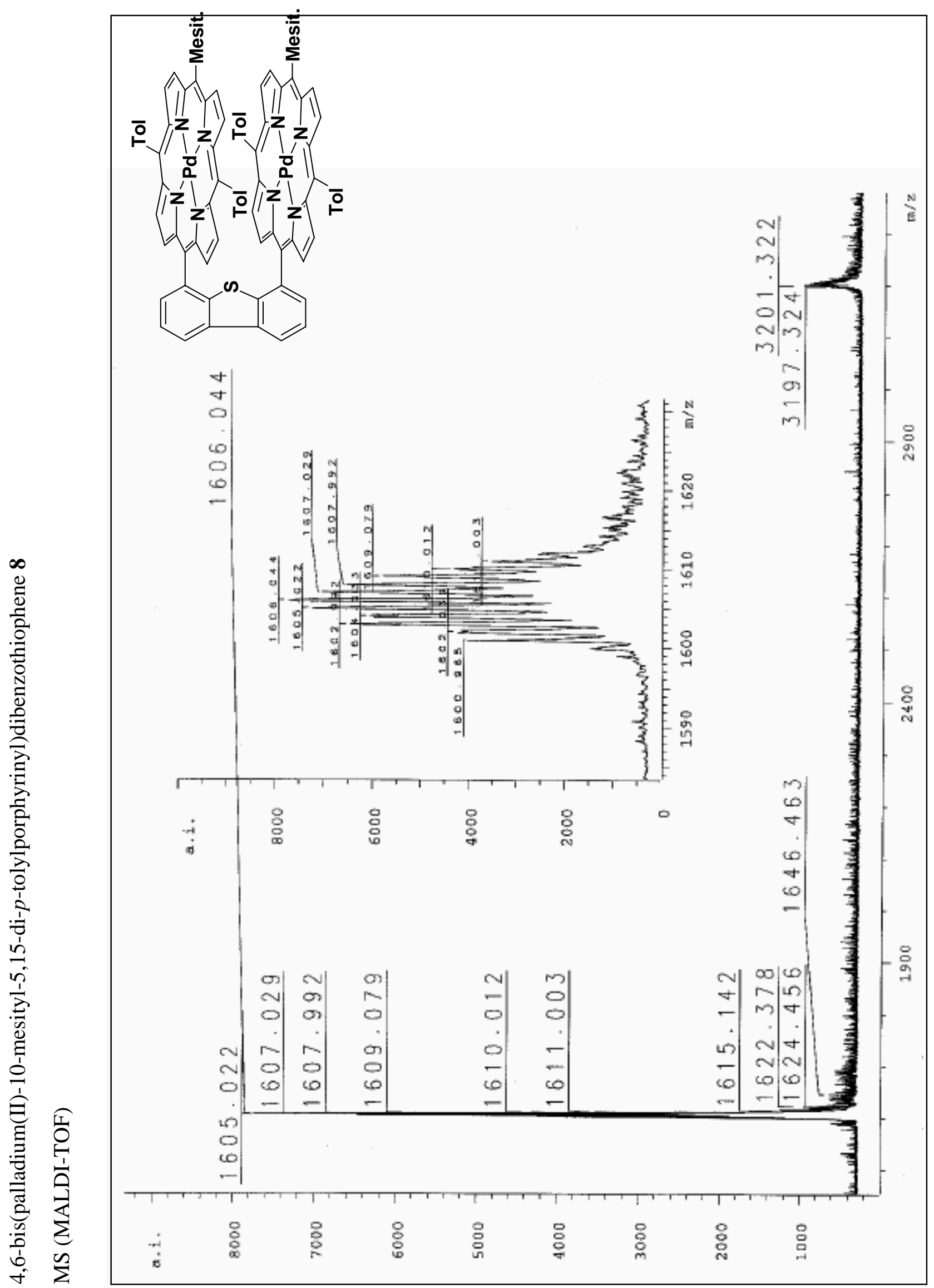




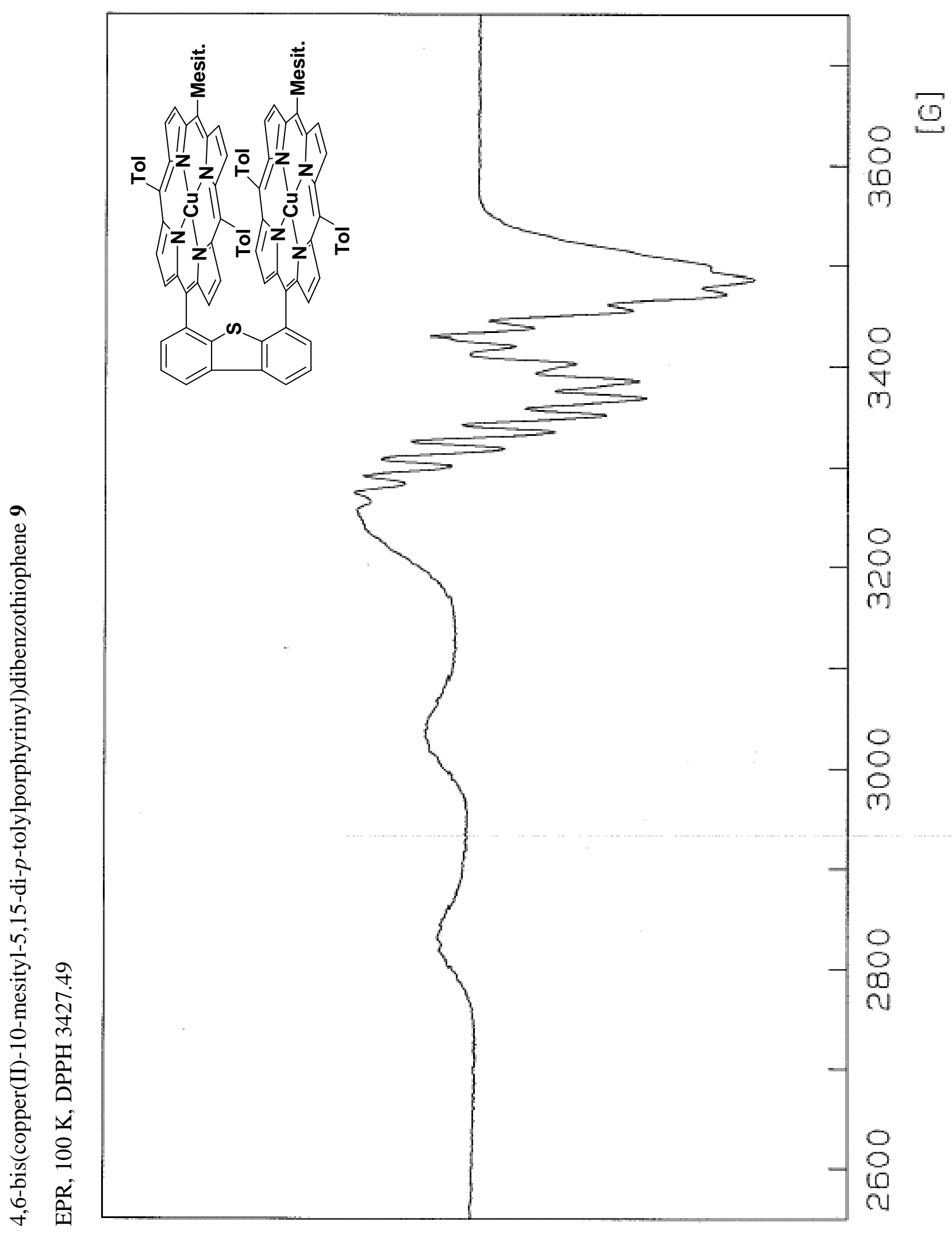




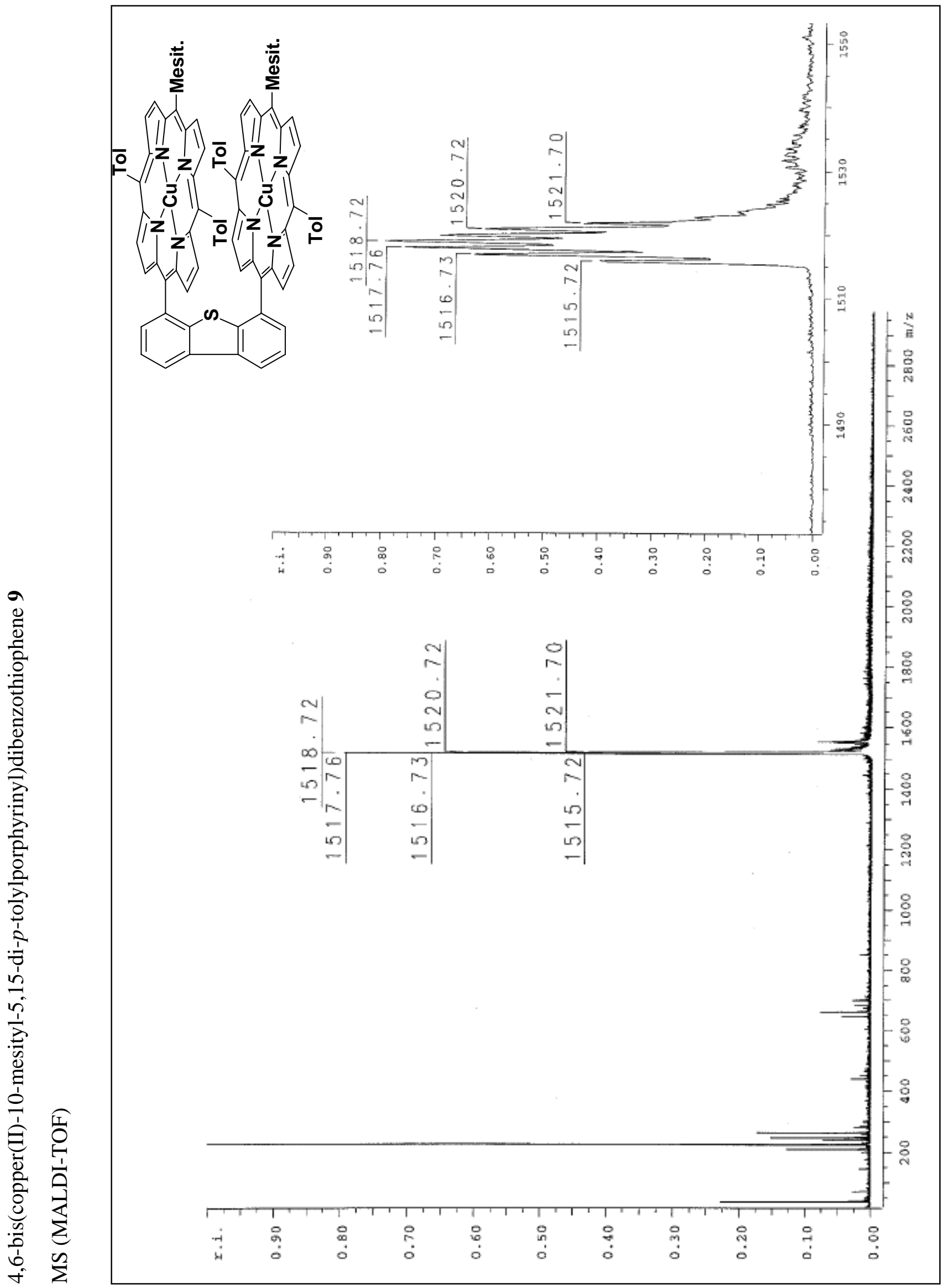




\section{References}

(1) Gouterman, M. In The Porphyrins; Dolphin, D., Ed.; Academic Press: New York, 1978; Vol. III, pp 1.

(2) Gouterman, M.; Khalil, G.-E. J. Mol. Spectrosc. 1974, 53, 88.

(3) Seybold, P. G.; Gouterman, M. J. Mol. Spectrosc. 1969, 31, 1.

(4) Harriman, A. J. Chem. Soc. Faraday Trans. 1981, 77, 369.

(5) Strachan, J.-P.; Gentemann, S.; Seth, J.; Kalsbeck, W. A.; Lindsey, J. S.; Holten, D.; Bocian, D. F. J. Am. Chem. Soc. 1997, 119, 11191.

(6) Harriman, A. J. Chem. Soc. Faraday Trans. 2 1981, 77, 1281.

(7) Murov, S. L.; Carmichael, I.; Hug, G. L. Handbook of Photochemistry; Second Edition ed.; Marcel Dekker: New York, 1993. 